\title{
The Consumer Behavior Analysis under Large Data Environment
}

\author{
Zhe Luo \\ Yunnan College of Business Management, China
}

Keywords: big data, consumer behavior, business model, consumption patterns change

\begin{abstract}
Big data has a large amount of information, various type, value the characteristics of low density, high speed and aging. With the development of the Internet, big data more and more showed an important role in the commercial competition, many companies use large data storage, calculation, analysis and multi-level business innovation. Under this background, the consumer contact with the changes in the way of goods, shopping show diversification, consumption concept and consciousness has been changed. Business consumer data is collection and the behavior analysis of the increasing to more data sources. Through the analysis of the characteristics of the large data, systematically explores the background in the era of big data the changes of consumer behavior, the business innovation are put forward based on this kind of behavior evolution trend.
\end{abstract}

\section{Introduction}

Early consumer behavior studies focus on consumer behavior wooden body, through the traditional questionnaire, focus group interviews, individual interviews, observation of qualitative and quantitative research approaches such as storefront and means to collect person II statistical data, shopping behavior and consumption intention information, such as used for research and analysis of consumer behavior. Entering the Internet age, reflecting the trajectory data of consumer behavior on the Internet is a large amount of precipitation, based on the shopping website hits and traffic and other network data by a large number of collection of the quantitative indicators, to form a summary and comprehensive description of consumer behavior path [1]. When cast into the era of big data, the network platform, style and diverse consumer shopping habits, needs to consumer data collection and analysis of the behavior gradually extended to more data sources, combining with the shopping website, other net around browsing information, and social media platforms, mobile terminals, search engines, such as multiple platforms to reach consumers, data mining, so as to make a comprehensive evaluation and analysis.

\section{The traditional consumer behavior research and the comparative analysis of the era of large data}

\subsection{Consumer behavior research model framework development.}

1898 Louis (E. S T. E lmo Lewis) proposed by the AIDA model is the study of consumer behavior as one of the hot theories, 1925 Edward. Keith trong on the four stages model of contact increases "MemoYV" (memory) stage, Chen Pei love, five phase type AIDMA model put forward in 2009.

AIDMA model is divided into concern an Interest generated from a Memory formation Action (Attention - Interest - Desire - the Memory - Action) five stages, to describe dynamic between audience from receiving information to produce Action to guide its psychological process and sequential pattern of a kind of law [1].

With the popularization of the Internet and mobile applications and information transmission media environment, profound changes have taken place, the audience relations change, audiences as the receivers of information and publishers to bear the dual role. 2005 mouth wood dentsu puts forward AISAS evaluation method of web2. 0 era background of divination, AISAS model is divided into five stages: pay Attention to the Share an Interest in a Search Action (Attention - Interest - Search - Action - Share), two of the traits of "s" - Search in the Internet background (Search) and ShaY 'e (Share), points out the importance of the Internet age blight consumer behavior (Beijing dentsu, 
2007). From AIDMA to transformation process of the AISAS model is based on web2. 0 era background of media and audience behavior change, created a new paradigm based on web2.0 Internet age assessment.

2011, mouth wood dentsu is released after AISAS "SIPS Model" analysis tool, the model is divided into four stages: echo a confirmed a participation in a sharing and diffusion (Sympathize - the Identify - Participate - Share Spread) (Cheng Shian, 2011). In humans into the time background of "dialogue", social individual and information relationships change, social individual initiative retrieval and sharing personal information, individual views gathered in one clangorous flock to scoop SIPS model the audience access to information, after resonate with the "confirm", "participation in action", "sharing and diffusion behavior of three links" express very clearly [1]. The model indicates the consumer behavior research into the digital age, thorough dissection of audience behavior platforms, based on the change of the digital age, Internet, mobile communication technology, channels and means for consumers to accept the information of change, so the need to switch to the multi-point, nonlinear scenes.

\subsection{Consumer behavior research path and change the way of data acquisition and development.}

For detailed history records of consumption at an early stage of tracking and analysis is the beginning of the deep understanding of consumer behavior, and today is realized from the understanding of consumer behavior to grasp consumer intentions to shift from track record consumer spending extension to the emerging data sources, such as net u cookies, social media platforms, mobile terminals, search engines, etc. The current many enterprises and brands have to obtain from the website to the consumer behavior of data integration in the whole strategy formulation, this data includes both consumers online trading, click, shopping path data, and data from social media sites, search engine [2]. The focus of the research is not just about how to dig the data, but delve into how to integrate all the valuable data, make a comprehensive analysis and evaluation. In addition, the traditional consumer behavior research is mainly to classify the collected data and survey results, from the macro level reading consumer data, limited to understand consumers' behavior when the terrorist. By big data technology integrating different platform data source, can be further subdividing data at different levels, can not only understand the consumer when blight and behavior, also can deep understanding of the consumer before the consumer action, help the whole marketing strategy formulation.

\section{The analysis of consumer behavior under big data era}

Professor at the Yale school of management levy dole (Ravi Dhār) is the leading experts in the field of brand marketing strategy, his description of the digital age, consumer decision-making behavior. At the time of doll came to China to lecture, FT conducted an exclusive interview to him. In the interview, dole for digital marketing era shared his brand and consumer behavior changes in anticipation [2].

First, dole argues that, in the age of social media, people in the online shopping will see other users' comments, because the user comments more credible than brand to provide product information, so user's reputation for brand more and more important. In the past, the brand to win by size, but now, if a customer group of brand good reputation and customer loyalty is high enough, can also stand out on the Internet.

Second, social media caused impact on the traditional advertising model. AD is a lot of big brands in the past, are to be carried out on large production, then large-scale advertising. But in the age of social media, is not the case [2]. Dole, for instance, Pepsi spent a huge sum of money made an AD, but the AD caused a tidal wave of criticism on social networks, Pepsi was forced to less than one day in the ads will be its emergency shelves, and a public apology, the negative emotions of social media can bring great impact to the brand. So, when the AD is brand to large-scale, want to think about the similar problem.

Third, Doll said, in the past there are a lot of products, such as gum by impulse buying. Most 
chewing gum is shelves in the supermarket next to the checkout counter, people have bought the checkout conveniently [2]. This impulse buying on line can also be in the past, but now a lot of consumer behavior in online, if a product particularly dependent on such spending patterns, then what should I do?Dole said, even if the consumer channels increases, also not necessarily can is worth impulsive consumption reduced, and the impact will come in two to three years.

Fourth, make it easier to excessive consumption without cash. Many studies show that cash more pain than a credit card. Dole said, you go to travel abroad, foreign money, because they don't feel really money and easy to spend more money. Now all kinds of mobile payments don't even need the card, you don't feel completely money spent from your hand, it'll be easier to spend more [2]. In addition, dole said, no cash transaction both sides feel more equal. If the taxi driver, he said in the past, when taking a taxi, better for him, he doesn't know the driver is really friendly, and hope he can give more tips. Now a taxi with software to take a taxi, passengers and drivers know that change is the fare, this will weaken the relationship between employments and hired.

\subsection{Consumer behavior is influenced by external introduce more easily.}

The traditional consumer often recommended by word of mouth, magazines to learn that the evaluation of the commodities, such as in the era of big data network, consumers can be directly in the post bar, BBS, microblogging, blog and other social media published its own subjective views, the evaluation information pass without reservation to newcomers [3]. As a result, the era of big data network of public evaluation more profound and extensive influence has a more direct on potential customers to buy influence. And public evaluation data will be reproduced or wider coverage, affect the consumers with more and more, the product of the purchase is also affected by a lot of, in this respect, Taobao, Jingdong, etc, on the basis of network marketing, based on cloud computing, with the help of the advertising push and flow drainage into consumers buy better.

\subsection{Consumer brand dependence gradually declines.}

According to the social chain of the growth of the brand, visibility, credibility, reputation, loyalty, dependency theory, traditional marketing era, visibility and reputation of the brand to a certain extent, depends on the quality of the product and word of mouth. In the era of big data, along with the science and technology progress and social development of famous brand products and ordinary products on quality gap is more and more small, youth pursuit individuation demand more and more high, to break the traditional chain brand growth of the society [3]. Make it become a take the quality as the premise, personalization for drive, hurried production cycle, chartered consumption coupled with the explosion of the Internet transmission speed and word of mouth effect, has brought the marketing worldwide attention and research. Consumers in a new round of technological change, to the brand reliance declining gradually have become a trend.

\subsection{Consumers to choose more personalized.}

With the continuous development of commodity economy, the new generations of consumers continue to strengthen to the attention of the individuality experience. Goods already beyond the simple material needs, and became the new way of being consumers, become the psychological security protection mechanism. Their consumption as a personal image, reflecting the mental world, releases the declaration of personality. With the aid of consumption, they express the desire for the freedom of choice, with the pursuit of personal fantasies; show the quality of the world [4]. Most China's enterprises only pay attention to the quality of the products for a long time and the performance of the product itself, but in the era of big data background, enterprises from the original single pursuit of quality and performance of the product itself into increasing external elements of the goods, in order to meet the personalized needs of consumers.

\subsection{Consumers' accurate analysis.}

Into the web the Internet age, the accurate segmentation study of consumer is divided into several stages, basically rely on site lock portal target positioning of the era of enterprise and brand marketing communication object, the era of search engine based on consumer active consumer segments in the 
form of keyword matching the social media era, through a wide range of channels to cover as much as possible more subdivided populations. Into the era of big data, the searches for more precise and detailed consumer segmentation to better achieve the goal step by step [4]. In the current study, the static database can be upgraded to real-time data flow, keeping track individual consumer online behavior, this track in addition to its consumer base wood information and shopping records, also include other web browsing habits, comprehensive information such as social media comments, reading be fond of, and big data technology can realize the consumers that the characteristics of online and offline information, line shopping records associated with traditional CRM, realize the enterprise and brand for the individual and group subdivided the multi-level marketing campaign evaluation of consumers.

\subsection{Consumer orientation and sentiment analysis.}

The "localization" contains two concepts, one is to track individual consumer behavior or search behavior of accurate positioning, through data analysis of user, classification and accurate transformation, such as the consumers in the process of browsing the web around has a propensity for what kind of information, products, and precision marketing; Second, based on the geographic location of the precise positioning, intelligent mobile terminal through the use of personal location push information to users. Based on the evolutionary data stream from the large number of social media users sentiment analysis evaluation provide the reference for a variety of consumer behavior analysis [4]. Enterprise and brand can be measured through the analysis of the emotional consumer real-time response to the marketing communication campaigns and quickly adjust accordingly. Such as Facebook "like" function and SinaWeibo and Tencent WeChat "like" function, can realize real-time feedback of consumer emotion. Because usually most consumers preferences and evaluation based on companion "word of mouth" make buying decisions, and emotional analysis in the process of consumer research is crucial.

\section{The consumer behavior business innovationunder the background of big data}

\subsection{Precision marketing in the application of business affairs development.}

The era of big data, enterprise hand holds the more and more users data, product data, and consumption data, how to use these data in a reasonable range create value and make it into a consumer purchasing power, become a problem urgently to be solved in enterprises. For the use of these data, accurate grasp the consumer psychology and behavior, production and sales of commodity consumer preferences, improve comprehensive service efficiency, precision marketing, will be a big data era under the background of enterprises to create value the best place to start [5]. Enterprise can through large data collection and sorting, analysis of the consumer business spending habits, determine the type and consumption preference, for accurate positioning, consumer to develop targeted portfolio of products, marketing planning and business decisions, and constantly find opportunities in the data analysis. In this regard, some enterprises have been one of the leading enterprises in the era, such as large data in Guizhou are built, implements the Wi-Fi throughout the city, through hard and fast rules will be moved to the government IT systems ali cloud, full intelligently analysis city weather, traffic, agriculture, government affairs law characteristics in real time as some adjustment, in 2015, there have been no death more than 3 people together of the traffic accident.

\subsection{All channel marketing combination, such as network marketing will become a trend.}

With the rapid development of information technology and e-commerce industry, the traditional sales channels in our country are facing a serious threat. On the one hand the rent prices continued to rise, labor costs continue to rise, the thinking mode of traditional enterprises lag behind, on the other hand under the impetus of the electronic commerce in the big data more comprehensive and accurate marketing expansion growth of online shopping, online and offline integration is imperative [5]. Electricity companies can use offline channels to supplement online for goods tactility and credit 
problems, at the same time, the traditional enterprise can also use electric business platform to improve the traditional single channel sales, radiation, and blind area is finite, and advertising. Under the background in the era of big data, the market will be more and more tend to be simple, quick, diversity, and requirements of the dealer channel construction is becoming more and more comprehensive and accurate, so the way of blending online will become a trend. In August 2016, for example, ali joins Su Ning purchase and strengthen cooperation.

\subsection{Business location.}

Big data era background, declining consumer loyalty, makes big data era business model must be from the brand as the center to consumer-centric [3]. In 2016, Alibaba is put forward to "the life cycle of consumers" to make sales. Fully reflects the commercial society now for the transition of the brand gradually increased to consumers as the center. In the industrial age, we are unable to know consumer's detailed data, but in the era of big data easy to acquire data of primitive accumulation and, with the aid of smart phones and worn equipment such as the development of science and technology, accurate data is becoming more and more, so businesses are more likely to comprehensive understanding of the consumer, can do one thousand "for consumers [6]. It is to increase the dependence of the product and loyalty. So in the future the competitiveness of the enterprises gradually shift to: who can provide professional products and services, who can fully understand and analyze the information, who will stand on the wave of business?

\subsection{The concept of business from is given priority to with goods to service transformation.}

Big data era, the knowledge level of consumer is more and more high, consumers will be a large number of data from existing in the comprehensive understanding of the function, value, etc. , if it's just at the mall or Internet simple introduce goods brand, packaging and using method is far cannot satisfy the needs of consumers [6]. Consumers on the basis of a large amount of data, to be aware of the product even better than the assistant, so companies must not only be very accurately the commodity structure, various performance indicators such as anatomy, must also provide a large number of solutions to consumers, namely enterprises sell the era of big data is not only a simple commodity, but the scheme of system integration services and goods [6]. Transformation is imperative, so from is given priority to with goods to give priority to with services, increase the loyalty of the customer for goods and dependence, for a new round of business change.

\section{Summary}

2016year is the development of big data, according to conservative estimates; the next big data market size will be at least one trillion Yuan above. Under the background in the era of big data, the changes of consumer behavior is becoming more and more uncertain, mobile Internet has accelerated the uncertain factors, electricity and traditional enterprise is becoming more and more inseparable from the data, the data will become the future enterprise's core competitiveness, enterprises should constantly improve their corporate governance structure, seize the market trend of change, make uncertain consumers, so as to do some one thousand people ", to provide personalized products and services, a place in the future competition.

\section{References}

[1] Sh. Zh. Wei, Big data marketing development present situation and its prospects, Modern business, 2014, vol. 5, pp. 15-18.

[2] L. J. Fu and G. T. Fan, The marketing of the era of large data change, China's commerce, 2013, vol. 5, pp. 66-68.

[3] J. T. Li, Based on the "big data" business model innovation, China's industrial economy, 2013, vol., pp. 23-26.

[4] T. J. Lu, The business model innovation of the era of large data, The Shanghai business, 2015, vol. 
3, pp. 43-47.

[5] Y. T. Huang, The application research of the era of large data, Computer programming skills and maintenance, 2014, vol. 8, pp. 25-28.

[6] F. J. Lu and B. Y. Lei, Consumer demand of the era of experience economy and marketing strategy, Beijing: China's industrial economy, 2002, vol. 8, pp. 81-86. 